Article

\title{
Quota Allocation for Carbon Emissions in China's Electric Power Industry Based Upon the Fairness Principle
}

\author{
Ming Meng, Lixue Wang * and Qu Chen \\ Department of Economics and Management, North China Electric Power University, Baoding 071003, China; \\ 51851341@ncepu.edu.cn (M.M.); ncepucq@ncepu.cn (Q.C.) \\ * Correspondence: ylxblx@ncepu.cn; Tel.: +86-155-3025-8606
}

Received: 6 August 2018; Accepted: 25 August 2018; Published: 27 August 2018

\begin{abstract}
As an essential measure to mitigate the $\mathrm{CO}_{2}$ emissions, China is constructing a nationwide carbon emission trading (CET) market. The electric power industry is the first sector that will be introduced into this market, but the quota allocation scheme, as the key foundation of market transactions, is still undetermined. This research employed the gross domestic product (GDP), energy consumption, and electric generation data of 30 provinces from 2001 to 2015, a hybrid trend forecasting model, and a three-indicator allocation model to measure the provincial quota allocation for carbon emissions in China's electric power sector. The conclusions drawn from the empirical analysis can be summarized as follows: (1) The carbon emission peak in China's electric power sector will appear in 2027, and peak emissions will be 3.63 billion tons, which will surpass the total carbon emissions of the European Union (EU) and approximately equal to $2 / 3$ of the United States of America (USA). (2) The developed provinces that are supported by traditional industries should take more responsibility for carbon mitigation. (3) Nine provinces are expected to be the buyers in the CET market. These provinces are mostly located in eastern China, and account for approximately $63.65 \%$ of China's carbon emissions generated by the electric power sector. (4) The long-distance electric power transmission shifts the carbon emissions and then has an impact on the quotas allocation for carbon emissions. (5) The development and effective utilization of clean power generation will play a positive role for carbon mitigation in China's electric sector.
\end{abstract}

Keywords: quotas allocation; carbon emissions; electric power industry; fairness

\section{Introduction}

China's carbon emissions have grown rapidly in recent years, from 3511.84 million tons in 2001 to 9232.58 million tons in 2017, with an average annual growth rate of $6.23 \%$ [1]. China surpassed the United States of America (USA) in 2006 to be the largest $\mathrm{CO}_{2}$ emitter in the world. At present, China's global $\mathrm{CO}_{2}$ emission share is as high as $27.61 \%$, much larger than the second (USA, $15.21 \%$ ) and the third (India, 7.01\%) largest emitters [1]. To control the global carbon emissions, and therefore mitigate the aggravation of the greenhouse effect, the European Union (EU), as the traditional core force in emission reduction, set a binding economy-wide domestic emission reductions target of at least $40 \%$ by 2030 compared to 1990 [2]. China has always maintained it will control its carbon emissions according to responsibility and capability. To cooperate with the international community to mitigate the global climate change, China pledged to achieve its peak $\mathrm{CO}_{2}$ emissions before 2030 and to make every possible effort to peak earlier in its INDCs (Intended Nationally Determined Contributions) to the Paris Agreement [3]. Besides, accompanied pollutants emitted with $\mathrm{CO}_{2}$ have been deteriorating China's local environments. More than $99 \%$ of the 500 largest cities in China do not satisfy the standards on 
air quality suggested by the WHO (World Health Organization), and 7 cities of the 10 most polluted cities worldwide are in China [4]. Therefore, China is facing tremendous pressure for carbon emission mitigation from both internationally and domestically.

Carbon emissions generated by energy are regarded as the prime contributor to the greenhouse effect, which is one of the most urgent issues around the world [5,6]. Due to resource endowments and excessive development of coal-fired power plants, thermal power generated more than $75 \%$ of the total electricity from the foundation of the People's Republic of China from 1949 to the present [7]. In 2015, the carbon emissions resulting from thermal power plants were approximately 4212.68 million tons in China (45.95\% of China's total), which far exceeded the country emissions of India (2218.43), the Russian Federation (1483.18), Japan (1207.79), Germany (753.64), Canada (532.5), and many other major emitters [1]. Fortunately, China's power industry has great potential for carbon reduction. Chinese carbon emissions per unit of electricity were almost $627 \mathrm{~g} / \mathrm{kWh}$ in 2015 [7-9], which is still far above that of the developed countries. As a major energy consumer and carbon emitter in China, the electric power industry is expected to be the main force for China's carbon mitigation, which is the first sector to be introduced into the carbon emission trading (CET) market in China.

CET is a market mechanism where the emitters can trade carbon emission rights as a commodity to promote global greenhouse gas emissions reduction [10,11]. Since 1997, when Kyoto proposed the concept of CET, it has been widely used and has achieved significant emissions reduction effects around the world. The European Union's carbon emissions trading system (EU-ETS), which was started in 2005, is the biggest CET system worldwide [12]. By 2015, there have been 17 CET systems spread across four continents, and the gross domestic product (GDP) of these systems has accounted for $40 \%$ of the global GDP. In December 2017, the NDRC (National Development and Reform Commission) of China formally announced the launch of the nationwide CET market in the electric sector. The total carbon emissions of CET in the electric industry will exceed 3 billion tons, outdistancing any other CET in the world [13]. There is no doubt that CET in China's power industry will play an essential role in carbon emissions reduction.

The quota allocation for carbon emissions is an important part for the successful operation of CET, which impact the price of carbon quotas and ensure the effectiveness of emissions reduction targets. It is well known that there are great differences in economic development levels, natural resource endowments, industry structure, and population across China. Therefore, the scientific and rational quotas allocation for carbon emissions is even more important to facilitate the establishment of the CET market in China's electric industry. However, the quota allocation scheme, as the key foundation of market transactions, is still undetermined. This research studies the quota allocation for carbon emissions in China's electric sector's CET from the perspective of capacity, responsibility, and potential for carbon mitigation, which can exactly reflect the economic development, industrial structure, and efficiency of carbon emissions, and then provide convincing evidence for quota allocation.

The traditional methods of carbon emission quota allocation can be defined as grandfathering [14,15], benchmarking [16,17], auction $[18,19]$, and so on. In addition to these traditional methods, an index method based upon fairness and efficiency was developed into a single-index and a multiple-index decision model. The latter is of particular interest to scholars because of the adaptive ability to address multi-dimensional differences among objects [20]. Wen et al. designed a comprehensive indicator model from the perspective of the capacity, responsibility, and potential for carbon emissions reduction [21]. To exactly measure the carbon efficiency, Qin et al. introduced a multi-criteria model combined with a weighted Russell direction distance model [22].

Apart from the method mentioned above, data envelopment analysis (DEA) is also a conspicuous optimization method. For example, Zhou et al. presented a DEA model with multiple abatement indexes considering the difference of marginal abatement cost in Chinese cities [23]. Based upon a non-radial Zero Sum Gains Data Envelopment Analysis (ZSG-DEA) model, Miao et al. efficiently allocated the carbon emission quota among Chinese provinces [24]. Zhou et al. introduced a DEA model based on spatial-temporal allocation strategies [25], which considered the imbalanced economic 
development and the discrepancy between development and carbon emissions. In addition, nonlinear programming and game theoretic approach have been advocated to explore optimal allocation of carbon emission permits. Liu et al. minimized the cost of carbon reduction to optimize the allocation for carbon emission quota based on a novel nonlinear programming method [26]. Stackelberg game models were employed by Ren et al. to study the quotas allocation for carbon emissions between the manufacturer and the retailer from the perspective of production [27]. An and Lee constructed a Stackelberg framework on the basis of a newsvendor non-cooperative game, which makes the target of carbon reduction come true by adjusting the individual and overall carbon quotas [28].

The current research related to carbon emission quota allocation is mainly concerned with the allocation between countries or regions. Little research has focused on the quotas initial allocation for carbon emissions from the perspective of industry, especially the power industry with a heavy proportion of carbon emissions. This paper allocates carbon emission quota for the Chinese power industry in 30 provinces from 2016 to 2030, providing a reference for China's national CET. Considering the striking differences that exist in the aspects of economics, resource endowment, and historical emissions [29], this study selected per capita GDP, historical accumulated per capita accumulated $\mathrm{CO}_{2}$ emissions, and $\mathrm{CO}_{2}$ emissions per unit of electricity as indicators based upon capacity, responsibility, and potential for carbon mitigation, respectively, to allocate the $\mathrm{CO}_{2}$ emission permission in the power industry.

This study carefully introduces a three indicators allocation model for CET in China's electric industry in Section 2. The data and the calculation of three indicators are included in Section 2. Section 3 describes the allocation results of the carbon emission quota. The detailed empirical analysis is discussed in Section 4, and then some policy suggestions are put forward. Section 5 summarizes conclusions of this paper.

\section{Methods and Data}

\subsection{Methods}

\subsubsection{Hybrid Trend Forecasting Model for Carbon Emissions}

To distribute the carbon quota in China's power sector, the total carbon emissions in the power sector (denoted as $C$ ) should be calculated first. The change of $C$ in China is mainly influenced by three factors: carbon emissions per unit of electricity (denoted as $\mathrm{H}$ ), electric consumption per unit of GDP (denoted as P), and GDP. The above three variables are closely related to C. $\mathrm{H}$ is the most efficient factor for carbon mitigation. The decrease of $\mathrm{H}$ means lower carbon emissions are required to meet the electric demand. With other variables remaining constant, the changes in $\mathrm{P}$ will affect the total electricity consumption and hence the $\mathrm{C}$. The impact of GDP on $\mathrm{C}$ is similar to that of P. Higher GDP will increase electricity consumption and correspondingly the carbon emissions will increase if other variables remain unchanged. Furthermore, GDP, $\mathrm{P}$, and $\mathrm{H}$ cover all the possible factors (compose $\mathrm{C}$ completely) that can be considered in energy policy making. Therefore, the relationship equation between $\mathrm{C}$ and GDP, $\mathrm{P}$, and $\mathrm{H}$ is described as

$$
\begin{aligned}
\mathrm{C} & =\mathrm{GDP} \times \mathrm{P} \times \mathrm{H} \\
& =\mathrm{GDP} \times \frac{\mathrm{E}}{\mathrm{GDP}} \times \frac{\mathrm{C}}{\mathrm{E}},
\end{aligned}
$$

where C, GDP, and E are the carbon emissions in the Chinese electric power industry, the gross domestic product, and electric generation of China, respectively.

In order to allocate carbon emission quota in China's electric sector, a forecasting method must be employed to predict GDP, P, and H in Equation (1). Influenced by economic and political factors, the three explanatory variables related to carbon emissions do not show a single linear or exponential relationship. The grey models, such as GM $(1,1)$ which is a trend extrapolate method generated by first-order accumulation of single variate, are popularly used to predict a small sample trend. 
Unfortunately, the representativeness of GM $(1,1)$ on the exponential growth trend is very limited and cannot represent all the exponential growth trends. In other words, only when the time-series data has a steady growth rate will GM $(1,1)$ can have a good fitting effect. Therefore, the grey prediction methods commonly used in homogeneous equation prediction are not suitable for this study. In order to forecast GDP, $\mathrm{P}$, and $\mathrm{H}$ more exactly, this paper adopts a hybrid trend extrapolation model [30], which can simultaneously fit the linear trend, exponential trend, and the combination trend of the two.

The homogeneous exponential and the linear fitting equations to a time series $x(k), k=1,2, \ldots, \mathrm{n}$, can be denoted as $\hat{x}_{(k+1)}=a \hat{x}_{(k)}$ and $\hat{x}_{(k)}=c k+d$, respectively. Then, the hybrid trend extrapolation equation can be expressed as

$$
\left\{\begin{array}{l}
\hat{x}_{(k+1)}=\hat{\lambda}_{1} \hat{x}_{(k)}+\hat{\lambda}_{2} k+\hat{\lambda}_{3}, k=1,2, \cdots \\
\hat{x}_{(1)}=x_{(1)}+\hat{\lambda}_{4},
\end{array},\right.
$$

where $\hat{\lambda}_{1}, \hat{\lambda}_{2}, \hat{\lambda}_{3}$, and $\hat{\lambda}_{4}$ are the estimated parameters.

Firstly, the estimations of $\hat{\lambda}_{1}, \hat{\lambda}_{2}, \hat{\lambda}_{3}$ are calculated. Let $\hat{\lambda}=\left[\begin{array}{c}\hat{\lambda}_{1} \\ \hat{\lambda}_{2} \\ \hat{\lambda}_{3}\end{array}\right], \mathbf{B}=\left[\begin{array}{ccc}x_{(1)} & 1 & 1 \\ x_{(2)} & 2 & 1 \\ \cdots & \cdots & \cdots \\ x_{(n-1)} & n-1 & 1\end{array}\right]$ and $\mathbf{Y}=\left[\begin{array}{c}x_{(2)} \\ x_{(3)} \\ \cdots \\ x_{(n)}\end{array}\right]$. Then, the estimation of $\hat{\lambda}$ by ordinary least squares (OLS) is

$$
\hat{\lambda}=\left(\mathbf{B}^{\prime} \mathbf{B}\right)^{-1} \mathbf{B} \mathbf{Y}
$$

By employing the results of the former parameters and the actual value of $x_{(k)}$, the result of $\hat{\lambda}_{4}$ is calculated as follows:

$$
\hat{\lambda}_{4}=\frac{\sum_{k=1}^{n-1}\left[x_{(k+1)}-\hat{\lambda}_{1}^{k} x_{(1)}-\hat{\lambda}_{2} \sum_{j=1}^{k} j \hat{\lambda}_{1}^{k-j}-\frac{1-\hat{\lambda}_{1}^{k}}{1-\hat{\lambda}_{1}} \hat{\lambda}_{3}\right] \hat{\lambda}_{1}^{k}}{1+\sum_{k=1}^{n-1}\left(\hat{\lambda}_{1}^{k}\right)^{2}},
$$

Let $k=1,2, \ldots$, in Equation (2), and the match value and predicting results to $x(k)$ can be gained.

\subsubsection{Principles and Indicators for Carbon Emission Quota Allocation Based on Equity}

Based on the current studies, three indicators are selected from the perspectives of equity and efficiency. This research selects per capita GDP, accumulated per capita carbon emissions from the electric power sector, and $\mathrm{CO}_{2}$ emissions per unit of electricity as indicators, which reflect the capacity, responsibility, and potential for carbon emissions reduction, respectively. Details of these criteria are presented in Table 1.

(1) Carbon reduction capacity.

The economically developed provinces can better afford and are more willing for carbon reduction. Wealthier regions have some essential conditions: sufficient funds, advanced technologies, and the relative optimized energy structure. In addition, the less-developed provinces are given priority to develop economy and narrow the gap of regional economic development. This means richer provinces with greater reduction ability will shoulder more responsibility for carbon emission-mitigation targets. This indicator is effective to measure the economic development of each province. The developed areas with higher per capita GDP will obtain fewer carbon emission quotas. Inversely, those regions 
with less per capita GDP will get more carbon emission quotas. This research employed the mean per capita GDP from 2011 to 2015 to quantify the economy of each province.

(2) Carbon reduction responsibility.

This criterion reflects the historical egalitarian principle, which cannot be ignored for equitable allocation for carbon emission quotas. The greenhouse gases emitted into the atmosphere cannot disappear immediately, and the capacity of the atmosphere is limited. In this sense, the developed provinces encroached on the future emission space of the developing provinces owing to the excessive carbon emissions during the historic economic development. Therefore, the areas that had high carbon emissions in the past should be given more responsibility for carbon mitigation and fewer carbon quotas. Conversely, the regions with low $\mathrm{CO}_{2}$ emissions historically should get more carbon emission quotas. In this study, the per capita accumulated carbon emission from 2011 to 2015 from the electric industry is employed to quantify the responsibility for carbon reduction of each province.

(3) Carbon reduction potential.

Carbon reduction potential is based on the perspective of cost equity for carbon reduction, which reflects the efficiency of energy utilization. For the economically developed areas, the technology of energy saving and emission reduction is relatively mature with efficient energy consumption, high cost of carbon reduction, and less potential for carbon emission reduction. For the economically backward provinces, the technology is relatively imperfect with poor efficient energy utilization, less capital investment into emissions mitigation, and more space for carbon emissions reduction. To minimize social emission reduction costs, more carbon emission quotas should be assigned in developed regions with higher emission reduction costs and less in developing regions with lower emission reduction costs. This research employed the mean of $\mathrm{CO}_{2}$ emissions per unit of electricity from 2011 to 2015 to quantify the potential for carbon mitigation of each province. The larger the indicator value, the lower the carbon quota should be and vice versa.

Table 1. Principles of carbon emission allocation.

\begin{tabular}{llll}
\hline \multicolumn{1}{c}{ Dimension } & \multicolumn{1}{c}{ Principle } & \multicolumn{1}{c}{ Interpretation } & \multicolumn{1}{c}{ Indicator } \\
\hline $\begin{array}{l}\text { Carbon reduction } \\
\text { capacity }\end{array}$ & $\begin{array}{l}\text { Economic } \\
\text { development }\end{array}$ & $\begin{array}{l}\text { The developed provinces should } \\
\text { undertake more responsibility. }\end{array}$ & $\begin{array}{l}\text { Per capita gross domestic } \\
\text { product (GDP) }\end{array}$ \\
\hline $\begin{array}{l}\text { Carbon reduction } \\
\text { responsibility }\end{array}$ & $\begin{array}{l}\text { Historical } \\
\text { responsibility }\end{array}$ & $\begin{array}{l}\text { Provinces with more historical } \\
\text { emissions should be more } \\
\text { responsible for carbon } \\
\text { mitigation. }\end{array}$ & $\begin{array}{l}\text { Historical accumulated } \\
\text { per capita carbon } \\
\text { emissions }\end{array}$ \\
$\begin{array}{l}\text { Carbon reduction } \\
\text { potential }\end{array}$ & $\begin{array}{l}\text { Carbon emission } \\
\text { efficiency }\end{array}$ & $\begin{array}{l}\text { Provinces with inefficient energy } \\
\text { consumption should take more } \\
\text { responsibility. }\end{array}$ & Carbon efficiency \\
\hline
\end{tabular}

\subsubsection{Allocation Model for Carbon Emission Quota}

Multi-criteria allocation models for carbon emission quota have received prominence among researchers because of their practicability. On the basis of the criteria introduced above, the allocation model for carbon emission quota can be written as follows:

$$
Y_{i, t}=\left(W_{1 i} X_{1 i}+W_{2 i} X_{2 i}+W_{3 i} X_{3 i}\right) \times C_{t}
$$

$Y_{i, t}$ is the carbon quota of province $i$ in year $t$ and $W_{1 i}, W_{2 i}$, and $W_{3 i}$ are the weights of three indicators. $X_{1 i}, X_{2 i}$, and $X_{3 i}$ are the percentage of per capita GDP, per capita accumulated $\mathrm{CO}_{2}$ emissions, and the mean of $\mathrm{CO}_{2}$ emissions per unit of electricity for province $i$, respectively. Since the values of the three indicators are inversely related to their carbon quotas, this means that the bigger the 
value is, the smaller the corresponding allocation will be. Therefore, this paper employs the following formula to achieve.

$$
\begin{aligned}
& z_{j i}=-\ln X_{j i}, j=1,2,3, \\
& Z_{j i}=\frac{z_{j i}}{\sum_{i=1}^{i=30} z_{j i}}, j=1,2,3,
\end{aligned}
$$

In addition, the Equation (5) could be written as

$$
Y_{i, t}=\left(W_{1 i} Z_{1 i}+W_{2 i} Z_{2 i}+W_{3 i} Z_{3 i}\right) \times C_{t}
$$

The entropy method was employed to calculate the weight of each indicator. Shannon introduced the definition of entropy firstly into information theory, and it has been extensively employed in many fields, such as engineering technology and social economy [31]. As a means to measure the disorder of the system, the basic idea of the entropy is to measure the objective weight based on the variability of the indicator [22]. In general, if the entropy of a certain index is smaller, it means that the greater the extent of variation of the index value, then the wealthier the information will be that is provided and it may play a more important role in the comprehensive evaluation and have greater weight. Inversely, the bigger the entropy of an indicator is, the smaller is the extent of variation of the indicator value, the poorer is the amount of information provided, the more insignificant is the role played in the system evaluation, and the smaller is the weight of the index. The steps can be concluded briefly as follows:

(1) Data normalization.

Since the measurement units of various indexes are not unified, it is necessary to normalize the data first. In other words, data normalization converts the absolute value of the index into a relative value so as to solve the homogeneity problem of different quality index values. In addition, the normalized processes of the positive and negative index value are different. The bigger value is better for positive indicators, but the smaller value is better for negative indicators. In addition, different algorithms should be employed to normalize the data for the two kinds of indexes, which are shown as follows:

Positive indicator:

$$
x_{k i}^{\prime}=\frac{x_{k i}-\min \left|x_{k}\right|}{\max \left|x_{k i}\right|-\min \left|x_{k}\right|}(k=1,2,3 ; i=1,2, \ldots 30),
$$

Negative indicator:

$$
x_{k i}^{\prime}=\frac{\max \left|x_{k}\right|-x_{k i}}{\max \left|x_{k}\right|-\min \left|x_{k}\right|}(k=1,2, \ldots 3 ; i=1,2, \ldots 30),
$$

(2) Calculate the share of sample $i$ in indicator $k$.

$$
u_{k i}=\frac{x_{k i}^{\prime}}{\sum_{i=1}^{n} x_{k i}^{\prime}}
$$

where $\sum_{i=1}^{30} u_{k i}=1$ 
(3) Calculate the entropy value of the indicator $k$.

$$
e_{k}=-(\ln 30)^{-1} \sum_{i=1}^{30} u_{k i} \ln \left(u_{k i}\right),
$$

If $u_{i k}=0$, then it can stipulate that $u_{k i} \ln \left(u_{k i}\right)=0$.

(4) Calculate the weights of indicator.

$$
W_{k}=\frac{1-e_{k}}{\sum_{k=1}^{3}\left(1-e_{k}\right)},(k=1,2, \ldots 3),
$$

At this point, the weights of indexes in Equation (8) can be obtained.

\subsection{Data}

\subsubsection{Measure of Carbon Emissions}

Since the data of carbon emissions from the electric sector have never been provided in China, it had to be calculated through the actual data of energy consumption [32]. Considering the consistency of the statistical caliber and proportion of energy consumption in the 30 provinces from the power industry, this paper selected nine energy sources: natural gas, refinery gas, fuel oil, diesel, crude oil, coke oven gas, other washed coal, cleaned coal, and raw coal. The carbon emissions can be obtained as follows,

$$
\mathrm{CO}_{2}=F C_{i} \times N C V_{i} \times C C_{i} \times O F_{i} \times \frac{44}{12},
$$

$F C_{i}$ is the energy consumption (standard coal measurement). $N C V_{i}$ is mean the net heating value factor [33]. $C C_{i}$ is the carbon content of energy selected from Intergovernmental Panel on Climate Change (IPCC) [34], which were widely used to estimate carbon emissions. $O F_{i}$ is carbon oxidation coefficient, which is generally $100 \%$; $\frac{44}{12}$ is the ratio of mass between a $\mathrm{CO}_{2}$ molecule and a $\mathrm{C}$ atom.

This paper employed the average value of "Middling" and "Peat" to represent the NCV of washed coal [35], because its composition is complex and uncertain. Similarly, the NCV of washed coal was replaced by the average NCV of "Oilfield Gas" and "Gasfield Gas".

\subsubsection{Data}

To forecast the total carbon emissions in China's electric industry, this research employed the annual data of GDP, energy consumption, and electricity generation in the Chinese power sector from 2001 to 2015. For the quota allocation to carbon emissions, the annual data of GDP, population, and energy consumption in the power industry of each province from 2011 to 2015 were collected from the China Statistical Yearbook (2012-2016). It should be noted that the price index was employed to reduce the impact of price fluctuation. In this article, energy consumption in thermal power represented the data of the electric industry. Energy consumption in the electric industry of each province and the total were, respectively, from the China Energy Statistical Yearbook (2012-2016) and the China Statistical Yearbook (2002-2016). Considering the data availability, this paper selected the related data of 30 provinces.

\section{Results}

\subsection{The Results of Carbon Emission Trends}

To obtain the trend of $C$ in Equation (1), a hybrid extrapolation method was employed to forecast the values of GDP, $\mathrm{P}$, and $\mathrm{H}$, respectively. Using the data of GDP, $\mathrm{P}$, and $\mathrm{H}$, the parameters were 
estimated and the trend extrapolation equations for GDP, $\mathrm{P}$, and $\mathrm{H}$ were calculated, respectively, as follows:

$$
\begin{gathered}
\left\{\begin{array}{l}
G \hat{D} P_{(k+1)}=0.4638 G \hat{D} P_{(k)}+347.7759 k+5721.8756, k=1,2, \cdots \\
G \hat{D} P_{(1)}=G D P_{(1)}-121.0431
\end{array}\right. \\
\left\{\begin{array}{l}
\hat{P}_{(k+1)}=0.4923 \hat{P}_{(k)}+0.006 k+0.0831, k=1,2, \cdots \\
\hat{P}_{(1)}=P_{(1)}-0.0026
\end{array}\right. \\
\left\{\begin{array}{l}
\hat{H}_{(k+1)}=0.3656 \hat{H}_{(k)}-8.9538 k+413.4115, k=1,2, \cdots \\
\hat{H}_{(1)}=H_{(1)}-0.9802
\end{array},(k=1,2, \ldots m),\right.
\end{gathered}
$$

Let $k=1 \sim 14$ and $k=15 \sim 29$ in Equations (12)-(14). Then, the fitting and forecasting results of the GDP, P, and H in years 2001-2015 and 2016-2030 were obtained, respectively, as shown in Figure 1a-c.

(a) GDP (triillion yuan)

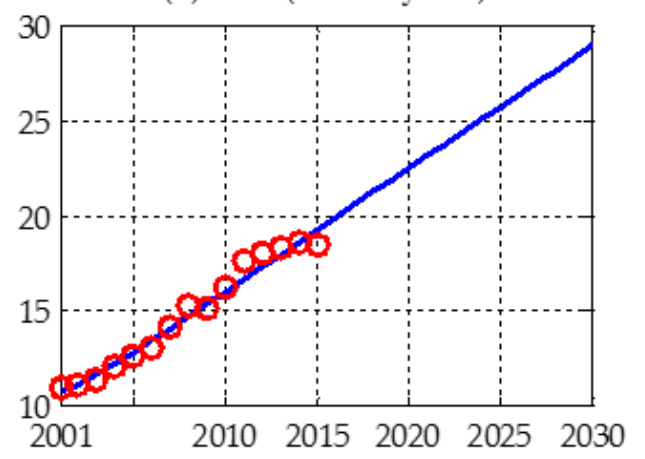

(b) $\mathrm{P}(\mathrm{kWh} /$ yuan $)$

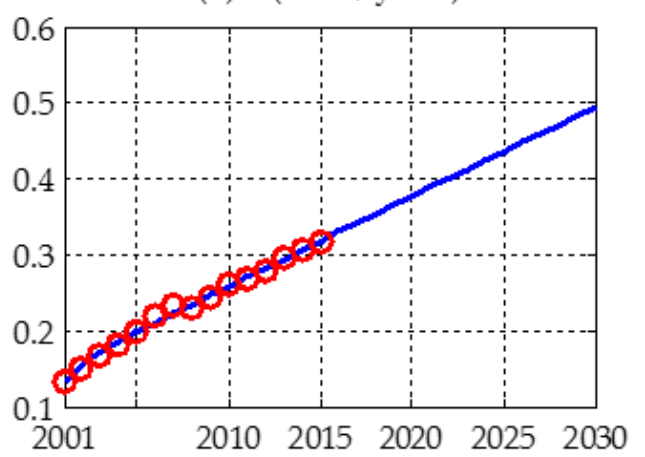

(c) $\mathrm{H}(\mathrm{ton} / \mathrm{kWh})$

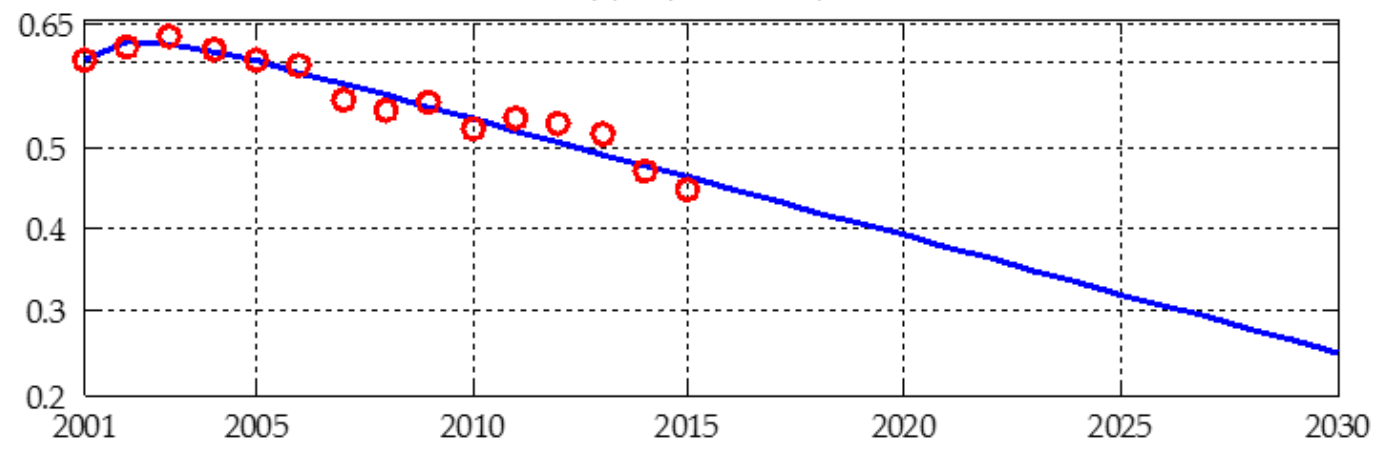

Figure 1. Fitting and forecasting results to the GDP, electric consumption per unit of GDP (P), and carbon emissions per unit of electricity $(\mathrm{H})$.

Figure 1a-c show that the historical trend, fitting results, and the forecasting trend of GDP, $\mathrm{P}$, and $\mathrm{H}$, respectively. As shown in Figure 1a,b, the GDP and P will keep growing before 2030. For GDP, it will increase to 22.43 and 28.92 (eliminating the effects of inflation) trillion yuan in 2020 and 2030, respectively. For $\mathrm{P}$, it will increase to 0.39 and $0.49 \mathrm{kWh} /$ yuan in 2020 and 2030, respectively, which is equal to 2 and 2.5 times of US's, respectively, and the average annual growth rate is still strong. This means that the electricity consumption required for the growth unit GDP is increased. H measures the efficiency of electric generation. Contrary to GDP and $\mathrm{P}$, the future trend of $\mathrm{H}$ is presenting a visible decreasing trend, which indicates the generation of electricity is becoming more efficient; this is conducive to realizing the sustainability development of China.

Based on the fitting and forecasting results to GDP, $\mathrm{P}$, and $\mathrm{H}$ above and in Equation (1), the trend of carbon emissions in the electric industry was obtained, as is shown in Figure 2. The forecasting 
results show that the carbon emissions in the electric industry exhibit an increasing trend from 2016 to 2027 with the growth rate decreasing. The carbon emission peak in China's electric power industry will appear in 2027 and peak emissions are 3.63 billion tons, which will surpass the total carbon emissions of the EU and approximately equal 2/3 of the USA (their carbon emissions have remained stable in recent years). The results indicate that China may achieve their commitment at the Paris climate conference, which is to attain a peak on carbon emissions before 2030 .

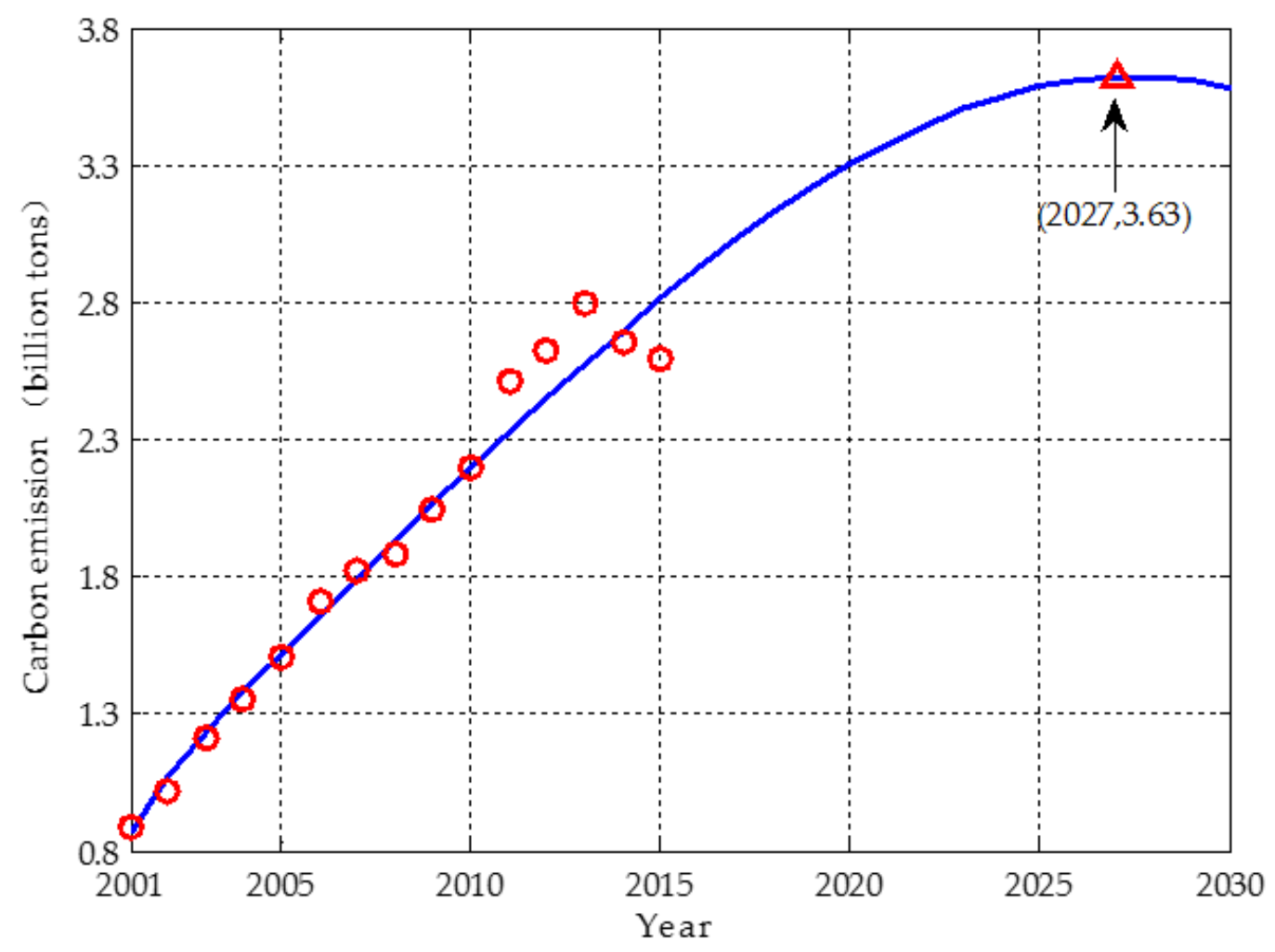

Figure 2. Fitting and forecasting results for the carbon emissions in the electric power industry.

\subsection{Results of Quota Allocation to Carbon Emissions}

The weights of indicators were obtained by Equations (9)-(13) and the results are listed in Table 2. For the three indicators, the proportion of carbon reduction responsibility is heaviest, which is high at 0.4011; the carbon reduction potential is smallest and the weight of carbon reduction capacity is in the middle.

Table 2. Weights for indicators.

\begin{tabular}{cccc}
\hline & $W_{1}$ & $W_{2}$ & $W_{3}$ \\
\hline Value & 0.3420 & 0.4011 & 0.2569 \\
\hline
\end{tabular}

The indexes of $\mathrm{CO}_{2}$ emission quota allocation of each province for the years 2016 to 2030 are listed in Table 3, which represent the share of $\mathrm{CO}_{2}$ emission quota of each province in each year. For example, the index of Beijing is 0.0343 , which indicates the quota from Beijing accounts for $3.43 \%$ of China's total in each year. The larger the value is, the higher the carbon emission quota will be, and the smaller the value, the lower the carbon emission quota will be. As can be seen from Table 3, Sichuan has the highest proportion at $4.12 \%$ and the smallest, $2.28 \%$, is in Ningxia. 
Table 3. Provincial shares for carbon emission quota.

\begin{tabular}{cccccc}
\hline Province & Share & Province & Share & Province & Share \\
\hline Beijing & 0.0343 & Zhejiang & 0.0323 & Hainan & 0.0274 \\
Tianjin & 0.0271 & Anhui & 0.0354 & Chongqing & 0.0366 \\
Hebei & 0.0351 & Fujian & 0.0330 & Sichuan & 0.0408 \\
Shanxi & 0.0304 & Jiangxi & 0.0374 & Guizhou & 0.0360 \\
Inner Mongolia & 0.0236 & Shandong & 0.0338 & Yunnan & 0.0412 \\
Liaoning & 0.0320 & Henan & 0.0361 & Shaanxi & 0.0333 \\
Jilin & 0.0316 & Hubei & 0.0322 & Gansu & 0.0353 \\
Heilongjiang & 0.0340 & Hunan & 0.0396 & Qinghai & 0.0329 \\
Shanghai & 0.0293 & Guangdong & 0.0357 & Ningxia & 0.0228 \\
Jiangsu & 0.0315 & Guangxi & 0.0394 & Xinjiang & 0.0298 \\
\hline
\end{tabular}

Figure 3 shows the summated carbon emission quota from 2016 to 2030 on the three indicators and the total of the three components of the provinces examined in this paper. A larger carbon emission quota indicates a smaller emission reduction obligation, and a smaller carbon emission quota indicates more responsibility for emission reduction. For example, Yunnan has the largest carbon emission quota, indicating that it bears less emission reduction duty and can focus on developing the economy. The $\mathrm{CO}_{2}$ emission quota of Inner Mongolia is the lowest, which indicates that the total scores of the comprehensive index on carbon reduction capacity, responsibilities for emission reduction, and potential for emission reduction are all high, therefore, Inner Mongolia must shoulder a heavier burden for emission reduction.

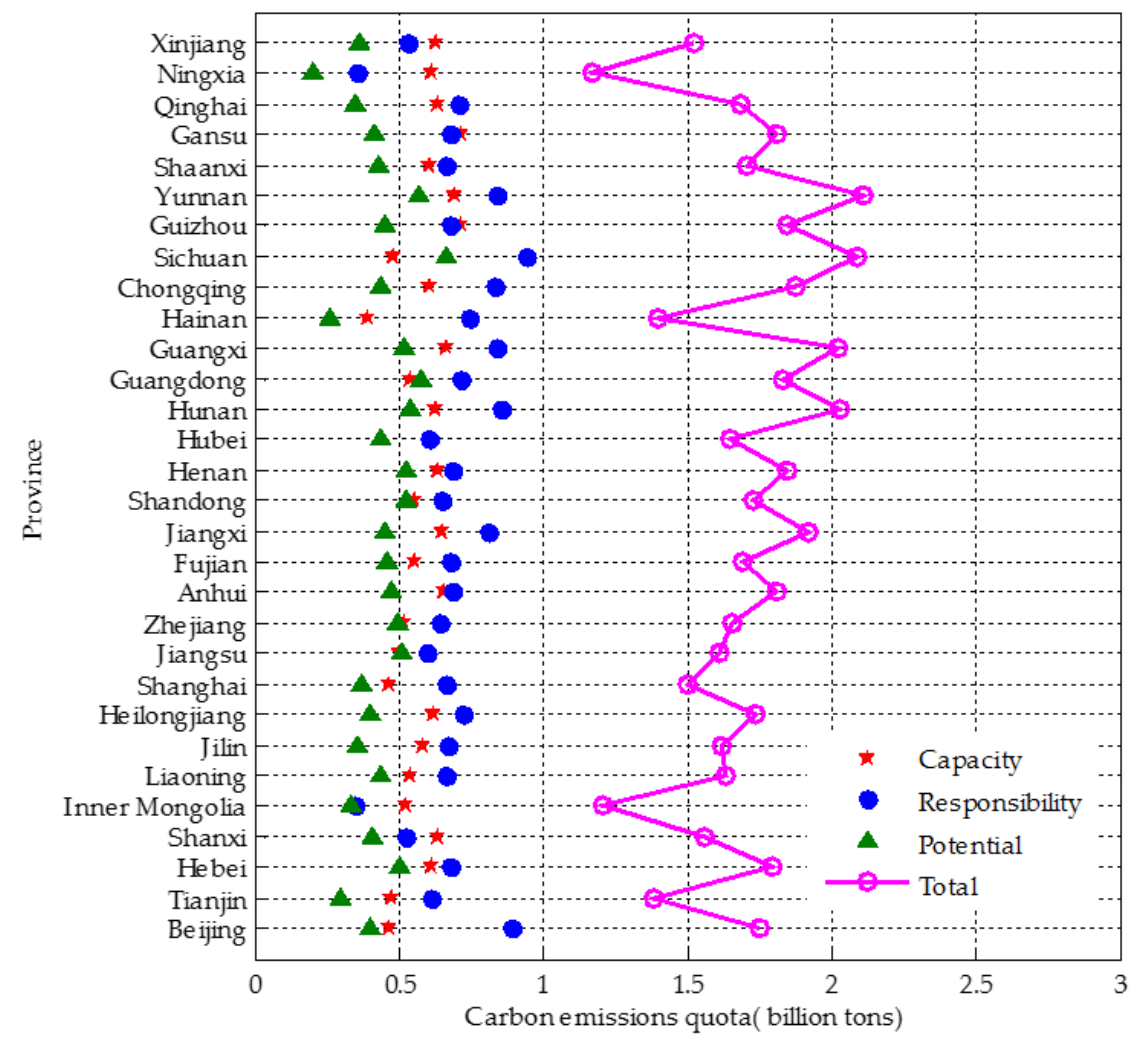

Figure 3. Carbon emission quota on indicators and the total for each province.

There are differences in economic development, historical carbon emissions, and power generation technologies among the provinces. Therefore, the carbon emission quota allocation obtained in terms of carbon emission reduction capacity, responsibilities, and potential also show great differences. 
For carbon emission reduction capacity, Hainan, Beijing, Tianjin, and Shanghai have higher per capita GDP and a stronger ability for carbon mitigation, therefore, these provinces have lower carbon quotas for carbon emission reduction capacity; those provinces with low per capita GDP, such as Guizhou and Yunnan, have higher carbon emission quota allocation for their low carbon emission reduction capability. On the basis of responsibility for carbon mitigation, per capita accumulated carbon emissions of Xinjiang, Shanxi, Ningxia, and Inner Mongolia are high in the period of investigation, so they should be more responsible for the target of carbon reduction and accordingly, their carbon emission quotas are small; in contrast, the provinces where the per capita accumulated carbon emissions in the investigated period are low will take less carbon reduction responsibility and obtain more carbon quotas in this indicator. For the indicator of the potential for carbon emissions reduction, the indicator values of Ningxia, Hainan, Qinghai, Xinjiang, Tianjin, et al. are relatively high, which indicates that these provinces have more potential for carbon emission reduction, so they obtained lower carbon quotas in this aspect; the carbon emissions per unit of electricity in Sichuan and Guangdong are relatively high and the potential for carbon mitigation is smaller, therefore, the quota obtained from carbon reduction potential are higher.

\section{Discussion}

Further study of the relationship between carbon emission quotas and actual carbon emissions is essential for China's electric industry's CET market. To obtain the actual carbon emissions of each province from 2016 to 2030, this study employed the mean of the carbon emission share from 2011 to 2015 as the actual carbon emission proportion from 2016 to 2030. In addition, the carbon quota remainder of each province can be defined as the difference between the total carbon quota and actual carbon emissions in 2016-2030, as demonstrated in Figure 4.

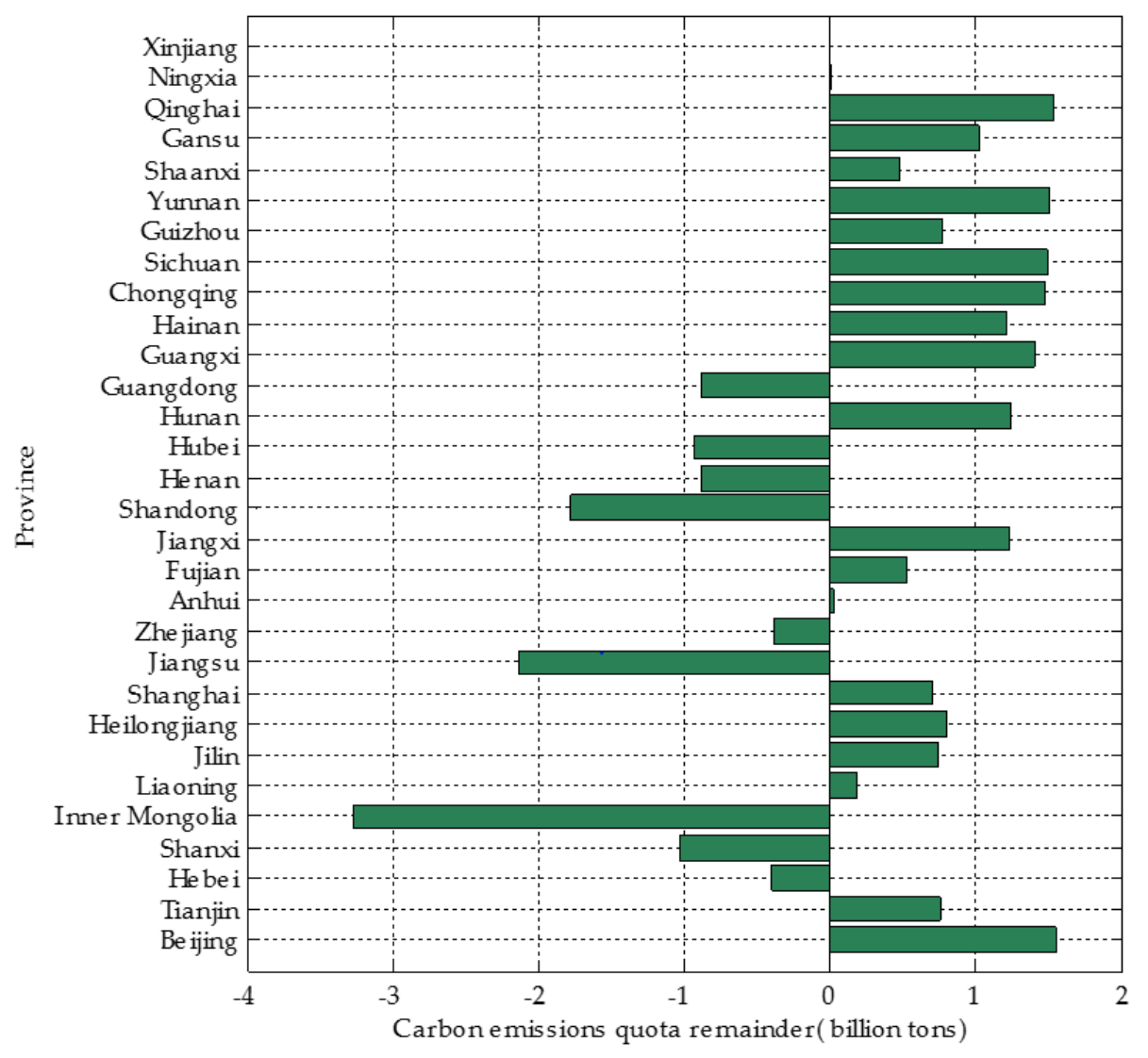

Figure 4. Carbon emission quota remainder of each province. 
Based on the value of carbon quota remainder, these provinces can be divided into three types: surplus, balance, and loss. For the positive value of carbon quota remainder, the carbon quota is bigger than the actual carbon emissions, in other words, the carbon quota of these provinces has a surplus. The greater the value of the carbon quote remainder, the more surplus will be obtained, such as in Beijing, Tianjin, etc., so these areas are expected to become the sellers in the CET market. When the value of carbon quota is zero, the carbon quota is equal to the actual carbon emission so the carbon quota is in balance. Considering the development of the economy and technology, theses provinces have a certain self-regulation, hence, Anhui, Ningxia, and Xinjiang are considered to be in states of equilibrium. For the negative values of the carbon quota remainder, the carbon quota is less than actual carbon emission. The carbon quota of the province suffers a loss and the smaller the value, the greater the loss will be, such as in Inner Mongolia, Jiangsu, Shandong, etc., these areas are excepted to be the buyers in CET market. As shown in Figure 4,70\% of the investigated provinces will be in balance or have a surplus, but there are nine provinces that will have a loss: Guangdong, Hubei, Shandong, Zhejiang, Jiangsu, Inner Mongolia, Hebei, Henan, and Shanxi.

For the nine provinces, there are different features in economic development, industrial structure, and efficiency of electric generation and resource endowments, which lead to diverse reasons for their carbon emission quota being in a loss. The main reasons are summarized as follows:

(1) Economy is developed. The provinces with a developed economy, which have high per capita GDP, can provide more sufficient financial guarantees for the research technology to reduce carbon emissions than do those regions with less economic development. Hence, developed economies obtained lower carbon quota, such as those in Jiangsu, Zhejiang, Inner Mongolia, and Guangdong. Those provinces that are abundant in carbon quotas but have a high per capita GDP should also contribute to carbon reduction because they have stronger capacity for carbon reduction, for example, Hainan, Beijing, Shanghai, Tianjin, Sichuan, and Liaoning.

(2) Actual carbon emission is huge. These provinces are the major carbon emitters in China and account for approximately 63.65 percent of China's carbon emissions generated by the power sector. Of the nine provinces, the total actual carbon emissions will all exceed 200 million tons except Xinjiang.

(3) Electric generation is inefficient. More carbon emissions generated per unit power means that the carbon emissions reduction is a potential, such as in Inner Mongolia, Xinjiang, and Hubei. Correspondingly, these provinces should bear more duty, and the carbon quota by this province is small. It should be noted that there are some provinces with surplus carbon quotas but with inefficient electric generation, such as Ningxia, Hainan, Tianjin, Qinghai, Jilin, Shanghai, and Beijing, which will also be responsible for reducing emissions. For those provinces, research and introduction of advanced electric generation technology is essential to mitigate carbon emissions.

(4) The share of traditional industries is high. These provinces are supported by traditional industries. The contribution of the traditional industries output of nine provinces was more than $61 \%$ during 2011 to 2015, and for three provinces, Guangdong, Shandong, and Jiangsu, it was more than $10 \%$ [6]. In addition, the traditional industries are dependent on electricity consumption, which mainly includes mining, manufacturing, electricity, gas and water production and supply, and construction. This explains the high carbon emissions in these provinces. For these provinces, accelerating industrial transformation and upgrading will ease the pressure on carbon emissions mitigation.

(5) The carbon emissions are shifted. The long-distance electric power transmission shifts the carbon emissions, and then has an impact on the quotas allocation for carbon emissions. It is well known that there are is a great diversity in resource endowments in China. In order to alleviate the connection between energy shortage and economic development in the east, China carried out the "West-East electricity transmission project", transforming the rich energy resources into electric power resources in the west and transporting them to the east coastal areas. This policy is conducive to the transformation of western energy resources advantages into economic advantages while relieving the pressure on the environment and transportation. However, this policy put the electric power output provinces at a disadvantage in carbon emission quota allocation. Those provinces generated more 
actual carbon emissions for electric power output and need to bear more carbon emission reduction duty, which means less carbon emission quota remainder than they should obtain. For example, Inner Mongolia and Shanxi, as sellers in the power market, provide a large amount of electricity for Beijing, Tianjin, and Hebei, leading to more carbon emissions, heavier carbon mitigation responsibility, and less carbon quota remainder. However, Beijing, Tianjin, and Hebei, as buyers in the power market, use part of the power with zero carbon emissions. This is equivalent to transferring carbon emissions from power buyers to the sellers and shifting the responsibility for carbon reduction too.

Figure 5 demonstrates the geographical location based on the carbon quota remainder. From Figure 5 it can be seen that the provinces in balance and in surplus are almost all located in the western, central, and northeast regions, while the provinces in loss are almost all in the east.

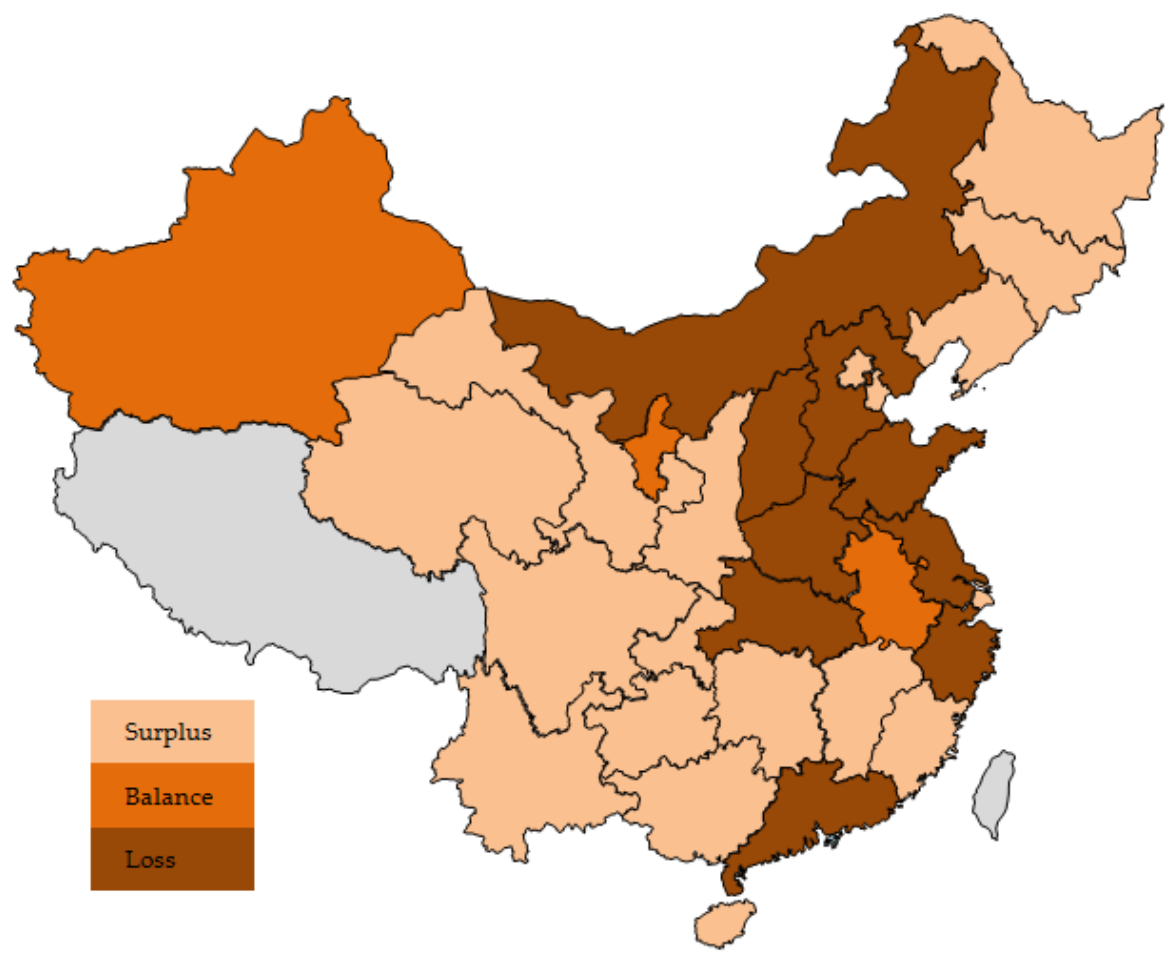

Figure 5. Geographical distribution of carbon quota remainder.

For the developed provinces in the east, the demands of electricity are enormous, but the electric generation is inefficient, so a large amount of carbon emission is inevitably produced. As the main force of carbon emission reduction, these provinces undertake more responsibility for emission reduction. This measure is conducive to research or introduction of advanced power generation technologies, restriction of the progress of carbon intensive enterprises, acceleration of industrial transformation and upgrading, and vigorous development of a low-carbon economy. The provinces with surplus carbon quota remainder located in the western and central regions lag behind in economic development. The CET market can bring economic benefits to these provinces and provide economic security for the introduction of advanced technologies to enhance electric generation efficiency.

\section{Conclusions}

As an essential measure to mitigate the $\mathrm{CO}_{2}$ emissions, China is constructing a nationwide CET market. The electric power industry is the first sector which was introduced into this market, but the quota allocation scheme, as the key foundation of market transactions, is still undetermined. To guide the development of the CET market, this paper researched the issue of carbon quota allocation in the electric power industry of China's 30 provinces from 2016 to 2030. 
This research employed the GDP and energy consumption and electric generation data of 30 provinces from 2001 to 2015 and a three-indicator allocation model to measure the provincial quota allocation for carbon emissions in China's electric sector. Furthermore, a hybrid trend forecasting model combined with a decomposition model was also used to predict the carbon emissions from the electric power sector. The conclusions drawn from empirical analyses are as follow: (1) The carbon emission peak in China's electric sector will appear in 2027 and peak emissions are 3.63 billion tons, which will surpass the total carbon emissions of the EU and approximately equal 2/3 of the USA. (2) The developed provinces driven by traditional industries will take more responsibility for carbon mitigation because of the excessive historical carbon emissions and high capacity for carbon reduction. (3) Nine provinces are expected to be the buyers in the CET market. These provinces are mostly located in eastern China, and account for approximately $63.65 \%$ of China's $\mathrm{CO}_{2}$ emissions from the electric sector. (4) The long-distance electric power transmission shifts the carbon emissions, and then impacts the quotas allocation. (5) The development and effective utilization of clean power generation will play a positive role for carbon mitigation in China's electric sector, which will reduce the percentage of electricity generation from fossil fuels, and then cut down carbon emissions.

Based on the above analysis, the following policy recommendations are put forward:

(1) Advanced power generation technologies should be advocated. The fundamental way to achieve carbon emission reduction is to make the power generation efficient, regardless of the provinces with a carbon quota loss such as Inner Mongolia, or provinces with surplus carbon allowances, such as Tianjin, Liaoning, and Jilin.

(2) Financial support and transfer payment. The provinces with greater carbon reduction responsibility are mostly featured with single industrial structures and inefficient electrical generation. However, technological improvement is a long process and cannot be accomplished overnight. Hence, provinces devoting themselves to mitigating the carbon emissions should be incented economically. Particularly, the government should provide financial assistance to these regions. Furthermore, as both the production provinces and the consumption provinces benefit from the interprovincial transmission, they should share the newly added emission cost. The transfer payment led by the government is a feasible measure.

(3) Regional cooperation. Regional cooperation is an essential means to achieve emission reduction targets. Buyers in the CET market are likely to be sellers in the electricity market. Buyers of carbon quotas can reduce the pressure of emission reduction, while sellers can obtain advanced power generation technologies and economic benefits. Not only can provinces achieve the goal of emission reduction, but also help to narrow the economic gap between regions and coordinate common regional development.

(4) Actively develop clean power generation. China is vast and rich in clean energy. Hydropower, wind power, solar power, and other clean power resources are abundant, but the utilization rate is low at present. For example, the degree of hydropower development in China is about 10 18\%, which is far below the world average level of $22 \%$ and the level of $50 \sim 100 \%$ in developed countries. Furthermore, the utilization of clean energy is insufficient. In 2016, the abandoned electricity generated by water, wind, and light reached up to 100 billion $\mathrm{kWh}$. Actively developing and sufficiently utilizing clean energy can reduce the share of thermal power, which will be conducive to the achievement of China's carbon mitigation goal and the improvement of the ecological environment.

Author Contributions: M.M. designed this research and provided some professional suggestions. L.W. wrote this paper. Q.C. reviewed this paper and proposed some valuable ideas.

Funding: This study was supported by the National Natural Science Foundation of China (NSFC) (71471061) and the Fundamental Research Funds for the Central Universities (2017MS171).

Conflicts of Interest: The authors declare no conflict of interest. 


\section{References}

1. Statistical Review of World Energy 2017. Available online: http:/ / www.bp.com/statisticalreview (accessed on 20 June 2018).

2. Effort Sharing 2021-2030: Targets and Flexibilities. Available online: https:/ / ec.europa.eu/clima/policies/ effort/proposal_en (accessed on 20 August 2018).

3. The Intended Nationally Determined Contributions (INDCs). Available online: http://www.China.org.cn/ chinese/China_key_words/2016-01/20/content_37622290.htm (accessed on 20 June 2018). (In Chinese)

4. Toward an Environmentally Sustainable Future: Country Environmental Analysis of the People's Republic of China. Available online: http:/ / www.Adb.Org/publications/toward-environmentally-sustainable-futurecountry-environmental-analysis-prc (accessed on 20 June 2018).

5. Smol, J. Climate change: A planet in flux. Nature 2012, 483, S12-S15. [CrossRef] [PubMed]

6. Wachsmuth, D.; Cohen, DA.; Angelo, H. Expand the frontiers of urban sustainability. Nature 2016, 536, 391-393. [CrossRef] [PubMed]

7. National Bureau of Statistics of the People's Republic of China. China Statistical Yearbook (2001-2015); China Statistics Press: Beijing, China, 2002-2016.

8. China Electricity Council. Annual Development Report of China's Electric Power Industry 2016; China Market Press: Beijing, China, 2016. (In Chinese)

9. Zhu, D. Analysis on advantages and disadvantages of initial allocation method for carbon emissions quota in electric power industry. Manag. Chin. Power Enterp. 2017, 1, 38-41. (In Chinese)

10. Guo, D.; Chen, H.; Long, R.; Ni, Y. An integrated measurement of household carbon emissions from a trading-oriented perspective: A case study of urban families in Xuzhou, China. J. Clean. Prod. 2018, 188, 613-624. [CrossRef]

11. Dai, H.; Xie, Y.; Liu, J.; Masui, T. Aligning renewable energy targets with carbon emissions trading to achieve China's INDCs: A general equilibrium assessment. Renew. Sustain. Energy Rev. 2018, 82, 4121-4131. [CrossRef]

12. Song, Y.; Liang, D.; Liu, T.; Song, X. How China's current carbon trading policy affects carbon price? An investigation of the Shanghai Emission Trading Scheme pilot. J. Clean. Prod. 2018, 181, 374-384. [CrossRef]

13. National Development and Reform Commission of China. Nation Construction Program for Building a Carbon Emission Trading Market in Electric Power Industry; National Development and Reform Commission of China: Beijing, China, 2017. (In Chinese)

14. Xu, J.; Yang, X.; Tao, Z. A tripartite equilibrium for carbon emission allowance allocation in the power-supply industry. Energy Policy 2015, 82, 62-80. [CrossRef]

15. Ji, J.; Zhang, Z.; Yang, L. Comparisons of initial carbon allowance allocation rules in an O2O retail supply chain with the cap-and-trade regulation. Int. J. Prod. Econ. 2017, 187, 68-84. [CrossRef]

16. Acquaye, A.; Genovese, A.; Barrett, J.; Koh, S.C.L. Benchmarking carbon emissions performance in supply chains. Supply Chain Manag. 2014, 19, 306-321. [CrossRef]

17. Dai, F.; Xiong, L.; Ma, D. How to set the allowance benchmarking for cement industry in China's carbon market: Marginal analysis and the case of the Hubei emission trading pilot. Sustainability 2017, 9, 322. [CrossRef]

18. Cong, R.; Wei, Y. Experimental comparison of impact of auction format on carbon allowance market. Renew. Sustain. Energy Rev. 2012, 16, 4148-4156. [CrossRef]

19. Liu, L.; Sun, X.; Chen, C.; Zhao, E. How will auctioning impact on the carbon emission abatement cost of electric power generation sector in China? Appl. Energy 2016, 168, 594-609. [CrossRef]

20. Zhou, P.; Wang, M. Carbon dioxide emissions allocation: A review. Ecol. Econ. 2016, 125, 47-59. [CrossRef]

21. Wen, J.; Zou, L.; Guo, J.; Wang, K.; Wei, Y. How can China reach its $\mathrm{CO}_{2}$ intensity reduction targets by 2020 ? A regional allocation based on equity and development. Energy Policy 2011, 39, 2407-2415.

22. Qin, Q.; Liu, Y.; Li, X.; Li, H. A multi-criteria decision analysis model for carbon emission quota allocation in China's east coastal areas: Efficiency and equity. J. Clean. Prod. 2017, 168, 410-419. [CrossRef]

23. Zhou, Z.; Liu, C.; Zeng, X.; Jiang, Y.; Liu, W. Carbon emission performance evaluation and allocation in Chinese cities. J. Clean. Prod. 2018, 172, 1254-1272. [CrossRef]

24. Miao, Z.; Geng, Y.; Sheng, J. Efficient allocation of $\mathrm{CO}_{2}$ emissions in China: A zero sum gains data envelopment model. J. Clean. Prod. 2016, 112, 4144-4150. [CrossRef] 
25. Zhou, P.; Sun, Z.; Zhou, D. Optimal path for controlling $\mathrm{CO}_{2}$ emissions in China: A perspective of efficiency analysis. Energy Econ. 2014, 45, 99-110. [CrossRef]

26. Liu, H.; Lin, B. Cost-based modelling of optimal emission quota allocation. J. Clean. Prod. 2017, 149, $472-484$. [CrossRef]

27. Ren, J.; Bian, Y.; Xu, X.; He, P. Allocation of product-related carbon emission abatement target in a make-to-order supply chain. Comput. Ind. Eng. 2015, 80, 181-194. [CrossRef]

28. An, J.; Lee, J. A newsvendor non-cooperative game for efficient allocation of carbon emissions. Sustainability 2018, 10, 154. [CrossRef]

29. Yu, S.; Wei, Y.; Fan, J.; Zhang, X.; Wang, K. Exploring the regional characteristics of inter-provincial $\mathrm{CO}_{2}$ emissions in China: An improved fuzzy clustering analysis based on particle swarm optimization. Appl. Energy 2012, 92, 552-562. [CrossRef]

30. Meng, M.; Niu, D.; Shang, W. A small-sample hybrid model for forecasting energy-related $\mathrm{CO}_{2}$ emissions. Energy 2014, 64, 673-677. [CrossRef]

31. Liu, W.; Cai, W.; Cui, B.; Wang, M. Synthetic evaluation method of electronic visual display terminal visual performance based on the letter search task. In Virtual, Augmented and Mixed Reality; Shumaker, R., Lackey, S., Eds.; Springer International Publishing: Cham, Switzerland, 2015; Volume 9179, pp. 30-38.

32. National Bureau of Statistics of the People's Republic of China. China Energy Statistical Yearbook (2011-2015); China Statistics Press: Beijing, China, 2012-2016.

33. GAQS (General Administration of Quality Supervision); IQPRC (Inspection and Quarantine of the People's Republic of China). Standardization Administration of the People's Republic of China, General Principles for Calculation of Total Production Energy Consumption; China Standard Press: Beijing, China, 2008. (In Chinese)

34. 2006 IPCC Guidelines for National Greenhouse Gas Inventories. Available online: http:/ /www.ipcc-nggip. iges.or.jp/public/2006gl/vol2.html (accessed on 20 June 2018).

35. Meng, M.; Jing, K.; Mander, S. Scenario analysis of $\mathrm{CO}_{2}$ emissions from China's electric power industry. J. Clean. Prod. 2017, 142, 3101-3108. [CrossRef]

(C) 2018 by the authors. Licensee MDPI, Basel, Switzerland. This article is an open access article distributed under the terms and conditions of the Creative Commons Attribution (CC BY) license (http:/ / creativecommons.org/licenses/by/4.0/). 